\title{
Counter-Rotating Type Pump-Turbine Unit Stabilizing Momentarily Fluctuating Power from Renewable Energy Resources
}

\author{
Toshiaki Kanemoto ${ }^{1}$, Risa Kasahara ${ }^{2}$, Hirotaka Honda ${ }^{2}$ and Toru Miyaji ${ }^{2}$ \\ 1. Faculty of Engineering, Kyushu Institute of Technology, Kitakyushu 804-8550, Japan \\ 2. Graduate School of Engineering, Kyushu Institute of Technology, Kitakyushu 804-8550, Japan
}

Received: January 27, 2014 / Accepted: March 04, 2014 / Published: June 30, 2014.

\begin{abstract}
It is difficult for renewable energy resources to provide constant power with excellent quality for the grid system. This serial research proposes a power stabilization system with a pumped storage to guarantee power quality and capacity, while the outputs from the energy resources are at unstable and/or fluctuating conditions. The power stabilization system with a counter-rotating type pump-turbine unit was prepared and operated at the pumping and the turbine modes. The unit composed of the tandem impellers/runners connected to the inner and the outer armatures of the unique motor/generator. The experiments have verified that this type pump-turbine unit is reasonably effective to stabilize momentarily/instantaneously the fluctuating power from the renewable energy resources.
\end{abstract}

Key words: Renewable energy, power stabilization, grid system, pumped storage, pump-turbine, counter-rotation.

\section{Introduction}

For the next leap in power technologies to get the sustainable society, it is important not only to cope with warming global environment but also to conserve natural ecosystem and coexist with nature. As for renewable energy resources in the world, hydro resources of about $2 \mathrm{TW}$ at the onshore, wind resources of about $72 \mathrm{TW}$, and marine resources more than $10^{3}$ TW (according to World Energy Council [1]) can be exploited newly. It is, however, too difficult to generate stable power from such resources whose circumstances are changed momentarily in response to weather conditions. On the contrary, a power station must provide the output with excellent quality for the grid system in general, through electric double layer capacitors, flywheels and/or electric accumulators.

Corresponding author: Toshiaki Kanemoto, research professor, research fields: hydrodynamics and turbomachinery. E-mail: kanemoto.toshiaki886@mail.kyutech.jp.
These devices, however, have limits for charging capacity, and their initial costs are expensive. On such circumstances, a power stabilization system with a pumped storage, namely a pump-turbine unit has been proposed in previous works by Murakami et al. [2] and Komaki et al. [3]. As for the proposed system, existing facilities, such as dam systems, water treatment systems and so on, can be utilized effectively to cut down the initial costs. The advanced technologies for the pumped storages are provided traditionally to the grid systems in cooperation with nuclear power generations to adjust the global power at day and night, and are recently having a key role as storing the wind power at EU as presented in proceedings [4]. Such technologies may be effective to slowly switch the operating mode every long period of time.

The technologies in this paper can stabilize momentarily/instantaneously the unstable/fluctuating power from the renewable energy resources. That is, 
this paper introduces the power stabilization system with the counter-rotating type pump-turbine unit $[2,3]$, and verifies fruitful performances of the unit at the pumping and the turbine modes.

\section{Power Stabilization System}

Fig. 1 shows the output from in-house Intelligent Wind Power Unit in the previous work by Nunoya et al. [5], and the output was averaged every one minute as shown in Fig. 2, where the average output was raised arbitrarily 16,000 times as high as one in Fig. 1. Conveniently, it is assumed here that a wind power station must provide constant power $P_{G}$ of $1 \mathrm{MW}$ for the grid system as follows.

Fig. 3 shows diagrams of the power stabilization system at a wind power station. The system is mainly composed of an electric accumulator with minimal capacity, a power control device and the pump-turbine unit. The output from the wind power unit is transmitted directly to the electric accumulator, and the power control device detects whether the output is higher or lower than $P_{G}$. The power control device demands the electric accumulator not only to provide the constant power $P_{G}$ for the grid system but also to operate the pump-turbine unit at the pumping mode by the surplus power, while the wind velocity is faster than that generating $P_{G}$, as shown in Fig. 3a. That is, the surplus output is stored, at once, as a potential energy

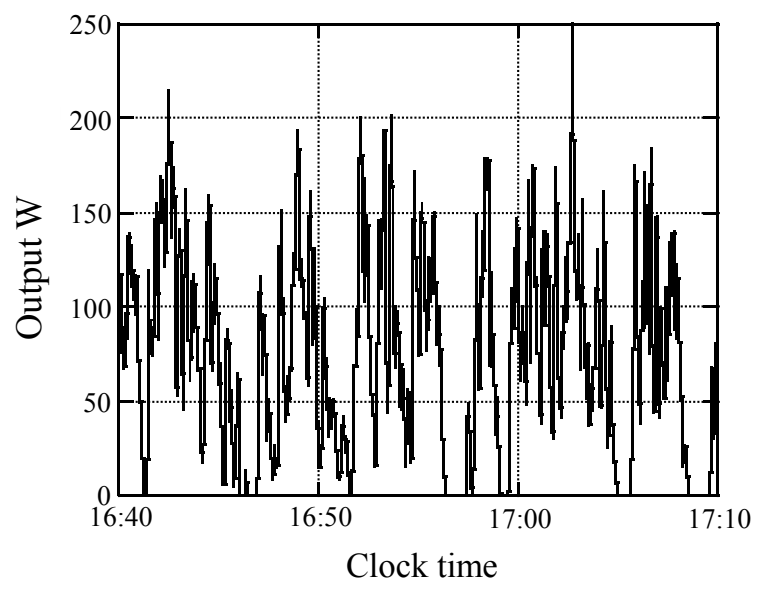

Fig. 1 Output from the in-house wind power unit.

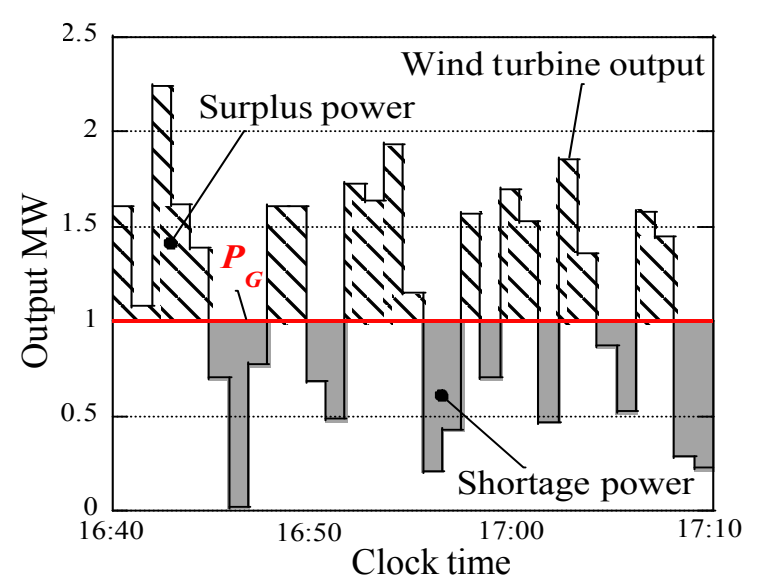

Fig. 2 Output averaged every $1 \mathrm{~min}$.

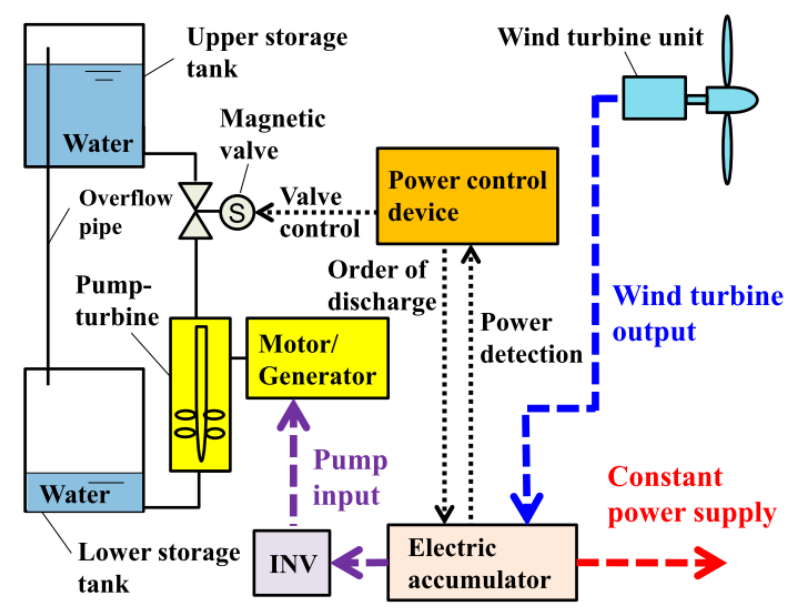

(a) Pumping mode

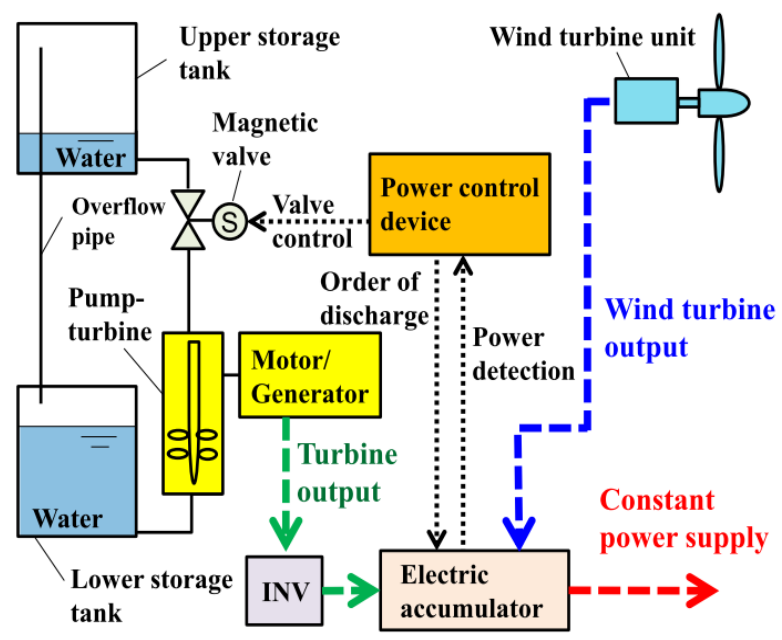

(b) Turbine mode

Fig. 3 Power stabilization system.

by the pumping mode. On the contrary, as shown in Fig. $3 b$, the power control device demands the pump-turbine unit to operate at the turbine mode 
converting from the stored potential energy to the hydroelectric output, so as to provide $P_{G}$ for the grid system with accompanying the shortage output from the wind power unit. That is, the pumping mode or the turbine mode is instantaneously determined every one minute in Fig. 2, judging from the output from the wind power unit. The final target of the serial research is to make the interval of time for the judgment as short as possible.

To put the above stabilization system into practical use, the pump-turbine unit which can appropriately work on demand from the power control device must be prepared.

\section{Counter-Rotating Type Pump-Turbine Unit}

The unique counter-rotating type pump-turbine unit was prepared for the above power stabilization system, where the impellers were designed exclusive for the pumping mode which is very important work for the pumped storage.

\subsection{Superior Operation at Pumping Mode}

Fig. 4 shows the model pump-turbine unit designed to get the best performance at the pumping mode and composed of the tandem impellers/runners and the peculiar generator-motor with the double rotational armatures. The inner and the outer armatures are connected directly to the front and the rear impellers or to the rear and the front runners, respectively. The inner and the outer armatures are driven at the conditions that the rotational torque is counter-balanced (Fig. $5 ; n_{M F}, n_{M R}$ : the rotational speed of the inner and the outer armatures, $M_{M F}, M_{M R}$ : the absolute rotational torque of the inner and the outer armatures). Besides, the relative rotational speed between both armatures is kept constant in the AC generator-motor at the pumping mode regardless of the shaft loads, which is specified with the frequency in the grid system. Then, the angular momentum change through the front impeller must coincide with that through the rear impeller (Fig. $6 ; u, v$ and $w$ are the impeller speed, the absolute and the relative velocity components, $\alpha$ and $\beta$ are the absolute and the relative flow angles at the impeller inlet and outlet). That is, the inner and the outer armatures drive the front and the rear impellers so as to counter-balance the rotational torques in keeping the relative rotational speed constant.

Assuming ideal flow condition and the axial flow at the front impeller inlet $\left(\alpha_{1}=0\right)$, the flow must run in the axial direction at the rear impeller outlet $\left(\alpha_{4}=0\right)$ irrespective of the discharge, in order to make the rotational torque of the rear impeller coincide with that of the front impeller. The thick solid lines in Fig. 6 show the velocity triangles at the normal (design) operation, where both impeller rotational speeds are the same. At the discharge smaller than the normal operation (dashed red line in Fig. 6), the rear impeller speed must decrease to get the axial flow at the impeller outlet, namely, to make the angular momentum change coincide with that of the front impeller. Resultantly, the rotational speed of the front

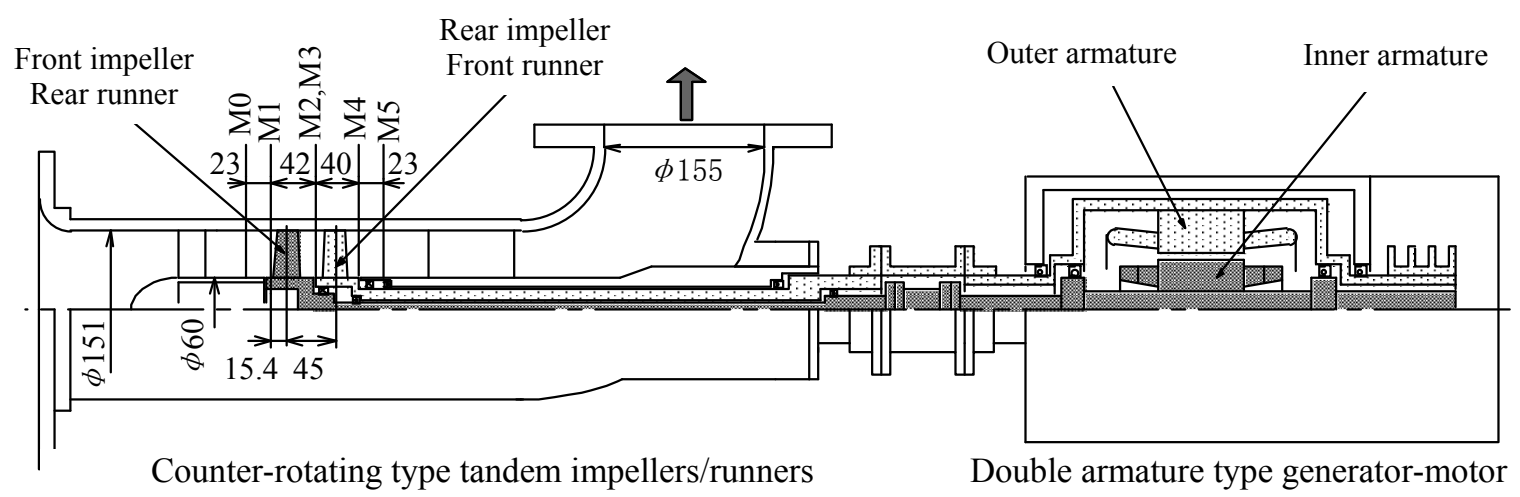

Fig. 4 Model counter-rotating type pump-turbine unit. 


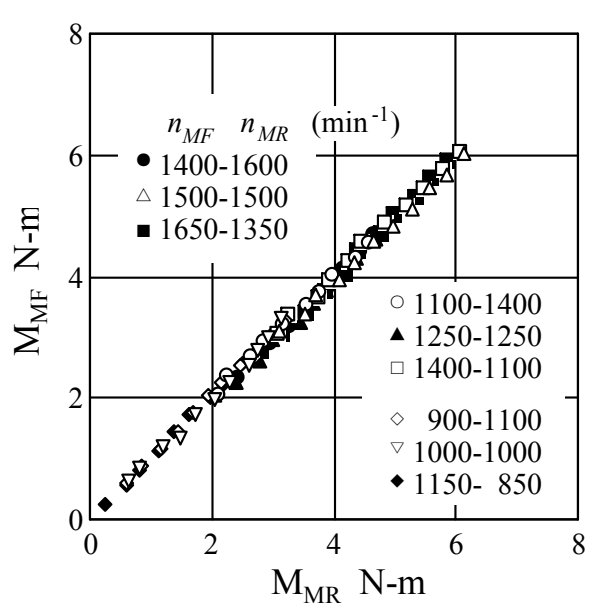

Fig. 5 Rotational torque acting on the armatures.

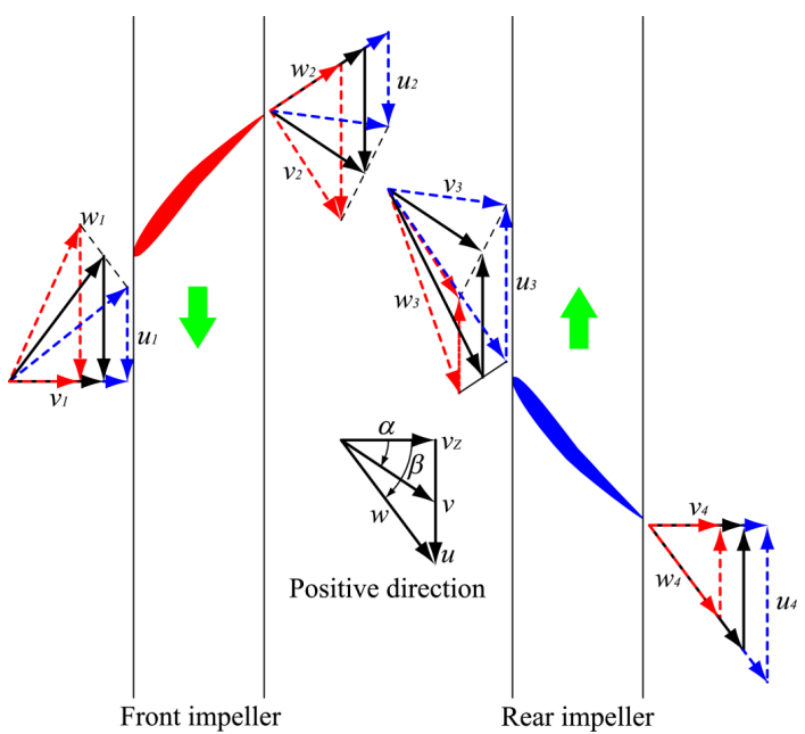

Fig. 6 Velocity through the tandem impellers in the ideal flow condition.

impeller is forced willy-nilly to increase for keeping the relative rotational speed constant. Such a front impeller has the reverse flow at the inlet due to the large angle of attack in actual flow with viscosity, which may make the pump operation unstable. The reverse flow also increases the rotational torque of the front impeller, and then the rear impeller speed must increase to give the swirling flow, which corresponds to the additional torque due to the reverse flow, at the rear impeller outlet (Fig. 7). The increase of the rear impeller speed makes the front impeller speed decreases to keep the relative speed constant. The decrease of the front impeller speed contributes not

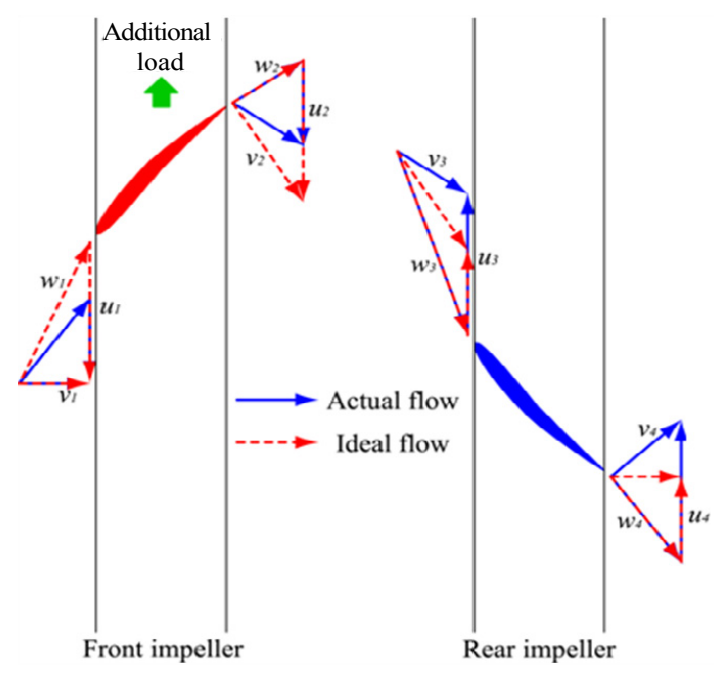

Fig. 7 Velocity through the tandem impellers at the low discharge in the actual flow condition.

only to decrease of the angle of attack but also to suppress fruitfully the reverse flow. The pump head lowering in the front impeller is successfully compensated by the head rising in the rear impeller with the higher speed. These operations suggest that the operation of the counter-rotating type unit is stable even at the low discharge.

At the discharge higher than the normal operation (blue dashed lines in Fig. 6), the rear impeller must run faster than the front impeller to make the swirl-less flow at the outlet. The front impeller at the slower speed works as if it were the inducer.

Above operating conditions scarcely depend on the operating mode. That is, the counter-rotating type pump-turbine unit, where the axial flow at the inlet brings the axial flow at the outlet without supplementary mechanism, is better suited to switch momentarily/instantaneously the operating mode, namely the flow directions at the pumping and the turbine modes.

\subsection{Preparation of Impellers/Runners}

The theoretical head is $H_{E T}=4.4 \mathrm{~m}$ and the discharge is $Q=1.78 \mathrm{~m}^{3} / \mathrm{min}$, at the normal (design) operation with the impeller speeds $n_{F}=n_{R}=1,500$ $\min ^{-1}$ (subscripts $F$ and $R$ denote the front and the rear impellers). The specific speed of each impeller is $n_{s}=$ 
$1,100\left(\mathrm{~m}, \mathrm{~m}^{3} / \mathrm{min}, \mathrm{min}^{-1}\right)$, and the specific speed as the counter-rotating type impellers is $n_{s t}=1,320(\mathrm{~m}$, $\mathrm{m}^{3} / \mathrm{min}, \min ^{-1}$ ). The diameter of both impellers is $D=$ $150 \mathrm{~mm}$, and the hub ratio is 0.4 . The number of the blades on the front and the rear impellers are 5 and 4 , respectively. The blade profiles are shown in Fig. 8, where $R \Theta$ and $Z$ are the distances in the tangential (circumferential) and the axial directions divided by the impeller diameter $D$, and called "Impeller" at the pumping mode, "Runner" at the turbine mode. Impeller A was derived from NACA4409 hydrofoil with a single arc camber, where the solidities of the front and the rear impellers are 0.75 regardless of the radial position [6]. Impeller $\mathrm{B}$ was designed numerically by the commercial code CFD to improve the pump performance [7], where the number of the blades and the meridian profile are the same as those of Impeller A. The solidities are larger and the thickness is 0.8 times thicker than those of the impeller A.

\section{Performance at Pumping Mode}

\subsection{Performance in Smart Control}

The peculiar operation of the proposed unit described above has been called "Smart Control" for fourteen years [6], as the unit suppresses automatically the unstable operation at the lower discharge and the cavitation at the higher discharge. To confirm the

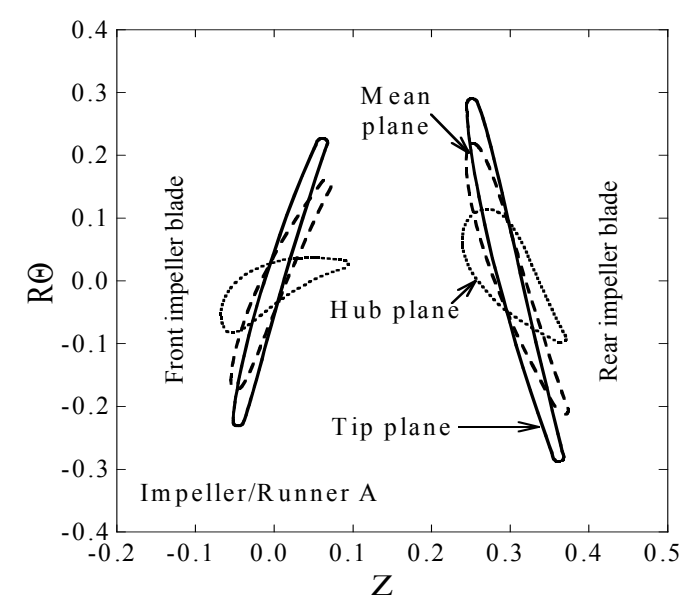

Fig. 8 Blade profiles on the tandem impeller/runners. smart control expected at the design stage, the pump performance was investigated in keeping the relative rotational speed constant at $n_{t}=3,000 \mathrm{~min}^{-1}$.

Fig. 9 shows the pump performance, where $Q / Q_{D}$ is the discharge ratio divided by the discharge at the normal operation, $\psi$ is the head coefficient [= $H /\left(u_{T}^{2} / 2 \mathrm{~g}\right) ; H$ : the head estimated from the static pressure at the casing walls between Sections M0 and M5 (Fig. 4), $u_{T}$ : the impeller tip speed at $\left.n_{T} / 2\right)$ ], and $N$ is the rotational speed $\left[=n /\left(n_{T} / 2\right) ; n_{T}\right.$ : the relative rotational speed]. Besides, $\tau$ is the input power coefficient $\left[=P_{I} /\left(\rho A u_{T}^{3}\right) ; P_{I}\right.$ : the input power to the generator-motor, $A$ : the projection area of the impeller], $\eta_{T}$ is total efficiency [ $\left.=\rho g Q H / P_{I}\right]$, the first subscripts $F, R$ and $T$ denote the front, the rear, and the tandem impellers, and the second subscripts $\mathrm{A}$ and $\mathrm{B}$ denote the impeller type Fig. 8. The input power coefficient $\tau_{B}$ and the efficiency $\eta_{T B}$ of Impeller B are obviously larger/higher than those of Impeller A. The input power means that the load of Impeller B is also higher than the load of Impeller A, as expected at the design stage.

The impeller speed is adjusted automatically, to meet the angular momentum change through the front impeller with that through the rear impeller. The rotational speed against the discharge has the same characteristics as expected at the design stage, but the impeller profile affects the speed at the discharge

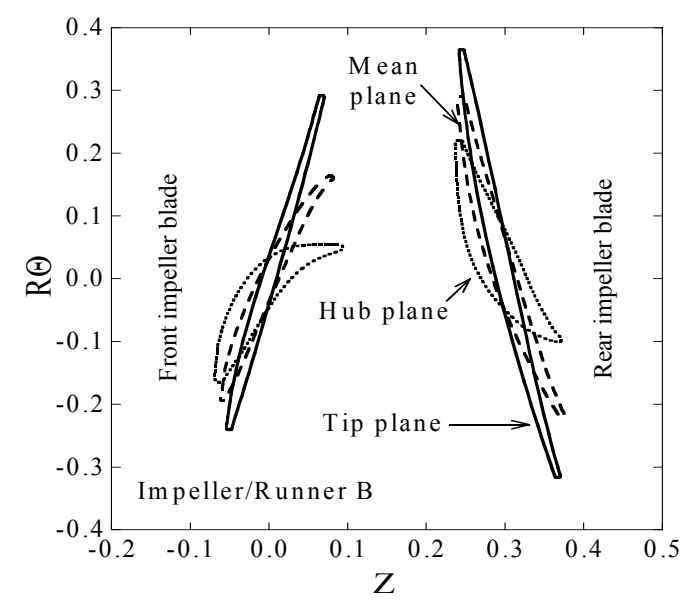



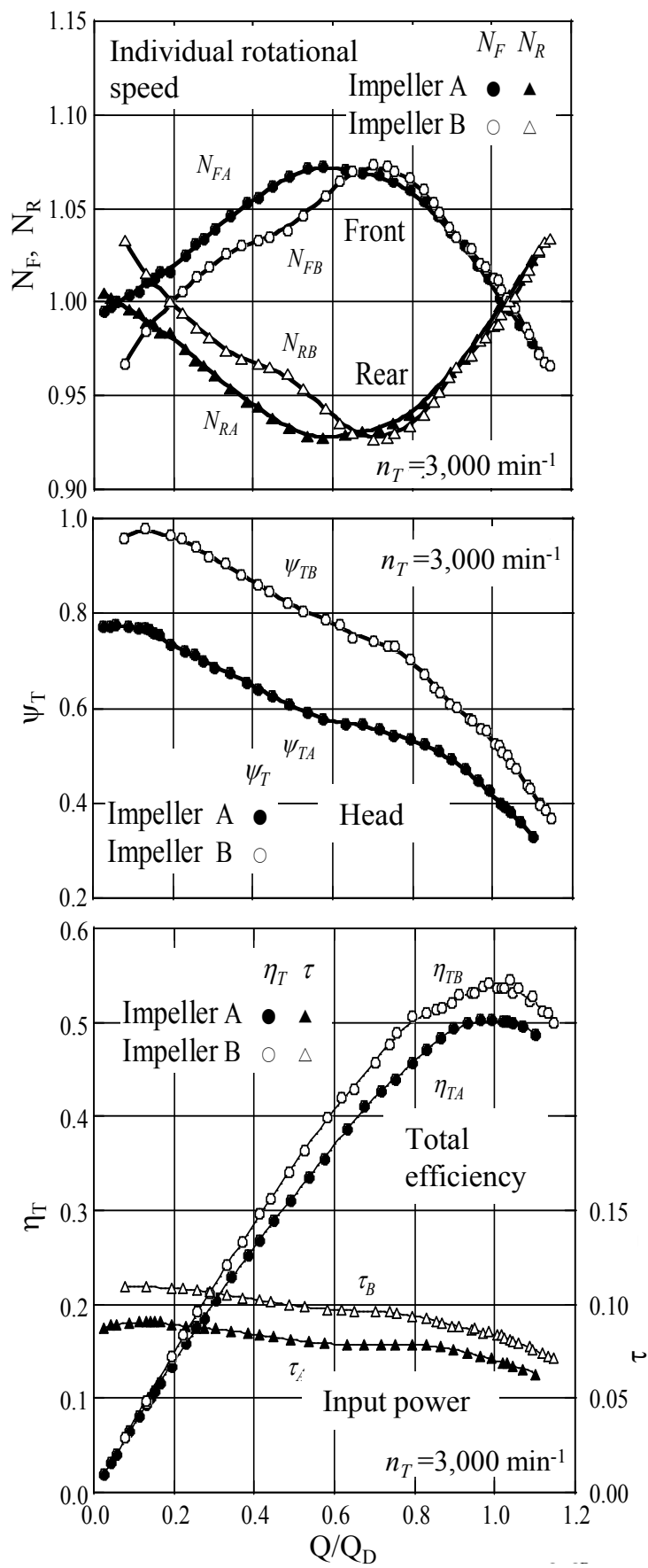

Fig. 9 Pump performance in the smart control.

lower than the discharge giving the maximum/minimum rotational speed.

The head coefficient of Impellers B $\psi_{T B}$ is higher than $\psi_{T A}$ of Impeller A, which contributes to improve the total efficiency $\eta_{T B}$ even though the input power $\tau_{B}$ is larger than $\tau_{A}$. It deserves special consideration that the head curved does not have the rising portion of characteristics, namely the unstable characteristics.

Kanemoto [6] and Oba [7] have also confirmed that the flow at the rear impeller outlet has no swirling component while the front impeller takes the swirl-less flow at the inlet.

\subsection{Performance at Pumping Mode}

Not only the turbine mode but also the pumping mode must be operated at the constant head, because the proposed stabilization system has the upper and the lower reservoirs/tanks at the fixed-sites (Fig. 3). Besides, the rotational direction must change continuously and immediately, between the pumping mode (positive) and the turbine mode (negative).

Fig. 10 shows the performances at the pumping mode in keeping the head constant $H=2 \mathrm{~m}$, where $N_{11}$ is the unit relative rotational speed $\left(=n_{T} D / H^{1 / 2}: \mathrm{m}\right.$, $\left.\min ^{-1}\right), P_{11}$ is the unit input $\left(=P / D^{2} / H^{3 / 2}: \mathrm{m}, \mathrm{kW} ; P\right.$ : the power without mechanical losses), $Q_{11}$ is the unit discharge $\left(=Q / D^{2} / H^{1 / 2}: \mathrm{m} \mathrm{m}^{3} / \mathrm{s}\right.$, the positive: pumping up), and $\eta_{h}$ is the hydraulic efficiency. The input power increases with the increase of the rotational speed, but the discharge is in the turbine flow at the slower speed, because not only the unit does not have the guide vane but also the piping system does not have the valve arrangement. The unit starts pumping up at $N_{11}$ faster than about $160 \mathrm{~m} \cdot \mathrm{min}^{-1}$ with higher input. That is, the rotational speed should be increased quickly to change the operation from the turbine to the pumping modes. The pumping mode takes the maximum efficiency of $\eta_{h}=78 \%$ for Impeller B and $68 \%$ for Impeller A at about $N_{11}=250 \mathrm{~m}, \min ^{-1}\left(n_{T}=\right.$ 2,360 $\left.\mathrm{min}^{-1}\right)$.

\section{Performance at Turbine Mode}

While changing the through flow and the rotational directions from the pumping to the turbine modes, the dimensions of the model pump-turbine unit are never modified but the inverter is in the regenerative braking control during the laboratory experiments. The front and the rear runners in the turbine mode correspond to 

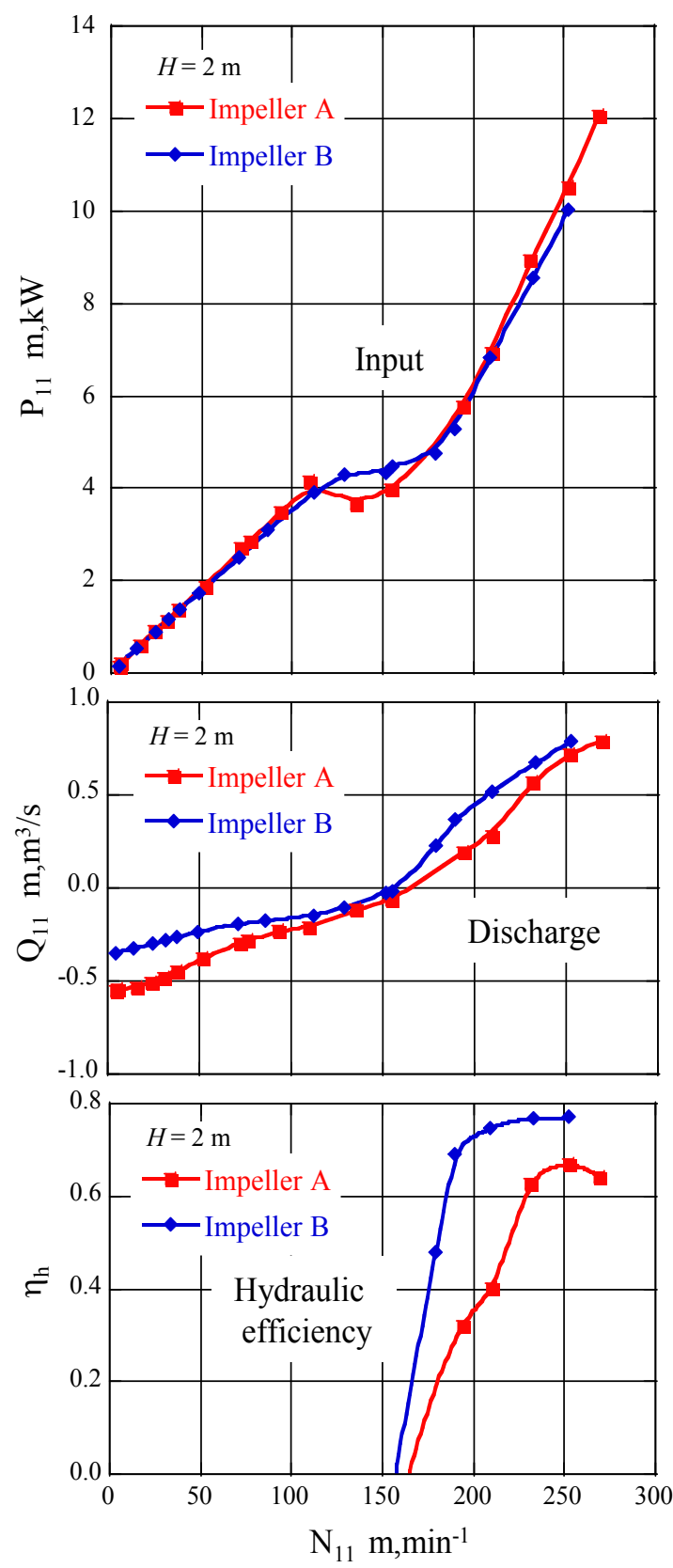

Fig. 10 Performance at the pumping mode.

the rear and the front impellers in the pumping mode, and the through flow attacks the cusped trailing edge of the impeller as confirmed in Fig. 8.

Fig. 11 shows the performance at the turbine mode in keeping the head constant $H=2 \mathrm{~m}$, where, $N_{11}$ and $Q_{11}$ take the negative values at the turbine mode. The flow passes through the runners while switching of the operating mode $\left(N_{11}=0\right)$, because the model unit and the piping system do not have the guide vane and the
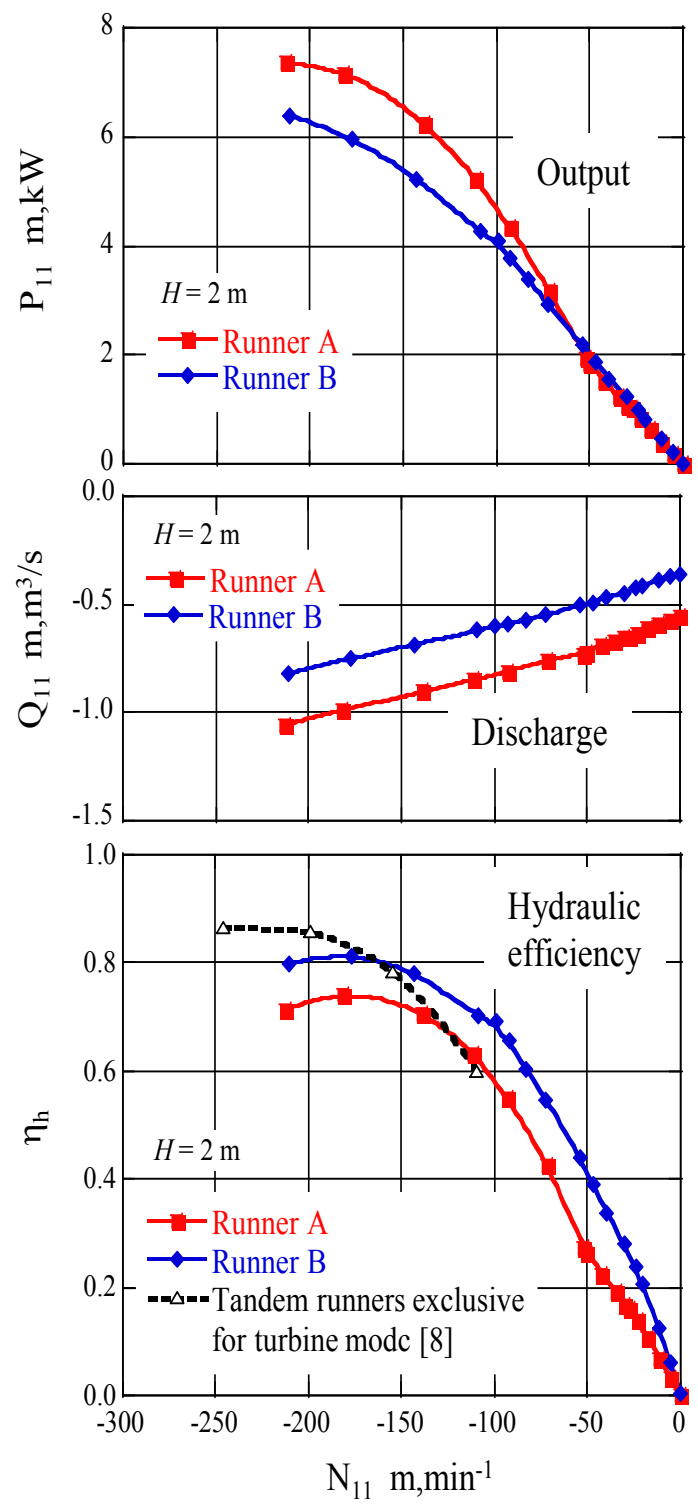

Fig. 11 Performance at the turbine mode.

valve arrangement as described at the pumping mode. It may be necessary to equip with the guide vane or the valve arrangement in the practical use. Making the rotational speed faster in the turbine mode, namely decrease of $N_{11}$, the output $P_{11}$ increases with the increase of the turbine discharge $Q_{11}$.

The maximum value of the hydraulic efficiency $\eta_{h}$ of Runner B is higher than that of Runner A. The dashed line in Fig. 11 gives the hydraulic efficiency of the counter-rotating type hydroelectric unit designed exclusively for the turbine mode by Kanemoto et al. [8]. The maximum hydraulic efficiency of Runner B is 
close to the efficiency of the hydroelectric unit (the maximum $\eta_{h}$ is near $87 \%$ [8] in Fig. 11), even though Runner B is designed exclusively for the pumping mode. The unit also has fruitful advantages that not only the induced voltage is sufficiently high without supplementary equipment such as a gearbox but also the rotational moment never acts on the mounting bed because the rotational torque counter-balances in the armatures/runner [8].

It was also confirmed by Komaki et al. [3] that the axial flow not only at the front runner inlet but also at the rear runner outlet rarely has a swirling velocity component regardless of the blade profiles, as the same as that in the pumping mode.

\section{Concluding Remarks}

The unique power stabilization system with the counter-rotating type pump-turbine unit was proposed to provide a constant power with high quality for the grid system. The operation of the stabilization system was expounded in response to the fluctuating output from the wind turbine. Besides, the counter-rotating type pump-turbine unit, designed exclusively for the pumping mode, was provided for the pumped storage.

Fig. 12 shows the complete performances of the model unit in keeping the head constant at $H=2 \mathrm{~m}$. The unit is at the pumping mode in Operating Range I and at the turbine mode in Operating Range V. The unit cannot pump up at $N_{11}$ less than about $160 \mathrm{~m} \cdot \mathrm{min}^{-1}$ in Operating Modes II and III, even though the rotational direction is in the pumping mode. The front and the rear impellers counter-rotate in Operating Mode II and both impellers rotate in the same direction as the rotation of the rear impeller in Operating Range III, where the impellers cannot pump up. In Operating range IV, the front runner rotates in the same direction as the rear runner, but the output can be got more or less.

The maximum hydraulic efficiency in the turbine mode is close to the efficiency of the counter-rotating type hydroelectric unit designed exclusively for the

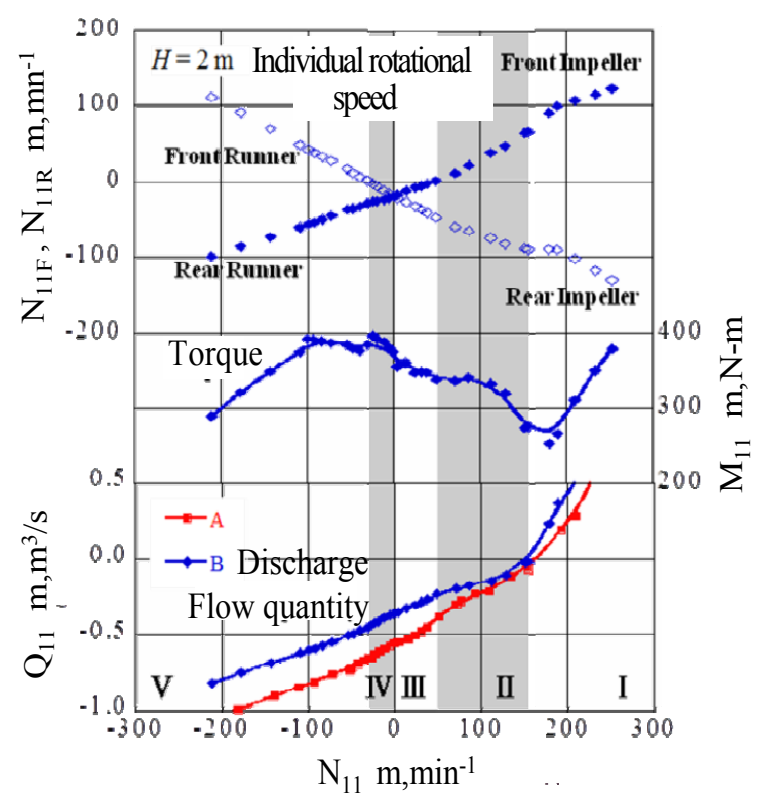

Fig. 12 Complete performance of the model pump-turbine.

turbine mode. Resultantly, this type unit is greatly effective to work in the power stabilization system proposed in this paper.

\section{Acknowledgements}

Some parts of this research were co-sponsored by the 24th (2012) Harada Memorial Foundation in Japan.

\section{References}

[1] World Energy Council, 2010 Survey of Energy Resources [online], http://www.worldenergy.org/documents/ser_2010_report _1.pdf (accessed Nov. 28, 2011).

[2] T. Murakami, T. Kanemoto, G. Takano, R. Kasahara, Numerical simulation in turbine mode of counter-rotating type axial flow pump (preparation of pump-turbine unit in cooperation with wind power unit), in: Proc. of the ASME 2012 Fluids Engineering Summer Meeting, Rio Grande, Puerto Rico, USA, July 8-12, 2012, pp. 1-7.

[3] K. Komaki, T. Murakami, T. Kanemoto, G. Takano, R. Kasahara, Counter-rotating type pump-turbine unit cooperating with wind turbine to stabilize instantaneously power supply (simulation in hydrodynamic work), in: Proc. 17th Int. Seminar on Hydropower Plants (Pumped Storage in the Context of Renewable Energy Supply), Vienna, Austria, Nov. 21-23, 2012, pp. 81-89.

[4] J. Dhillon, Topic: Pumped storage with 24 papers, in: Proc. 17th International Seminar on Hydropower Plants (Pumped Storage in the Context of Renewable Energy 

Power from Renewable Energy Resources

Supply), Vienna, Austria, Nov. 21-23, 2012, pp. 53-309.

[5] T. Nunoya, C. Takata, K. Makita, T. Kanemoto, Field test of intelligent wind power unit, in: Proc. 2011 ICOWEOE Conf., Beijing, China, Nov. 1, 2011.

[6] T. Kanemoto, S. Kimuraq, S. Oba, M. Sato, Smart control of axial flow pump performance by means of counter-rotating type, Trans. Japan Society of Mechanical Engineers, Series B 66 (651) (2000) 2927-2933. (in Japanese)

[7] S. Oba, T. Kanemoto, Design of counter-rotating impellers by inverse method to improve pump performances, in: 22th IAHR Symposium on Hydraulic Machinery and Systems, Stockholm, Sweden, June 29-July 2, 2004, pp. B09-1.doc-1(9)-B09-1.doc-9(9).

[8] T. Kanemoto, D. Tanaka, T. Kashiwabara, M. Uno, M. Nemoto, Tidal current power generation system suitable for boarding on a floating buoy, International Journal of Offshore and Polar Engineering 11 (1) (2001) 77-79. 